\title{
The Role of Diversity in Company Productivity: The Case of the Bank Sector in Kosovo
}

\author{
Bardha Mulhaxha ${ }^{1} \&$ Berim Ramosaj $^{1}$ \\ ${ }^{1}$ University of Pristina "Hasan Prishtina", Faculty of Economics, Republic of Kosovo \\ Correspondence: Bardha Mulhaxha, University of Pristina "Hasan Prishtina", Faculty of Economics, Department \\ of Management and Informatics, Str. "Agim Ramadani", p.n. 10000 Pristina, Republic of Kosovo. E-mail: \\ bardhamulhaxha@hotmail.com
}

Received: November 17, 2021; Accepted: December 15, 2021; Published: December 16, 2021

\begin{abstract}
Importance to identifying how diversity affects individual and group productivity in todays globalized world is increasing. The purpose of this research lies in the phenomenon of diversity and further analysis of the impact that diversity has on the work environment. To conduct this research, I interviewed 20 managers and 30 employees of the banking sector regarding the composition of their staff with emphasis on diversity. The data were processed using the statistical analysis of SPSS program. Human resources have positively influenced the increase of success, productivity and has eased problem solving, bettered performance, training, salary, and diversity of employees. This study will have practical significance in the easier approach of problems in human resource management and their motivation.
\end{abstract}

Keywords: diversity, productivity, innovation

\section{Introduction}

Diversity is an inevitable part of our daily life, everything we have in front of us belongs to diversity. The novelty of this paper lies in the fact that no paper that has studied diversity has included indicators such as age, group diversity and easier problem solving as a key factor in increasing the productivity of the company.Diversity in the workplace is defined as recognition of the group of people who share a common trait (Mfene, 2010). The more variety in the workplace, the greater the number of ideas and thus the easier the solution to problems. Each company consists of individuals who constitute the core resource of any company. Operating in an environment that changes every day, the readiness of human resources to deal with the problems that companies face every day is also of great importance. The readiness and ability of the staff to react in a timely manner also depends heavily on its composition in essence. At this point an important factor is the diversity of employees, starting from their age, gender, culture, religion, etc. The diversity dimension is a mainstay of modern organization culture mainly because managers are anxious to reap diversity-related advantages such as increased perspectives on how to solve problems and how to better relate to diverse customers. (Certo, S. C., \& Certo, S. T. 2013).Diversity in the workplace is not something new, as we see that there are many individuals who emigrate to different countries but are accepted and welcomed in workplaces where they can also be an advantage.Organizations work with and through people, and as such human resources are the most important asset of organizations. Developing staff and gaining new knowledge creates a resource that contributes to the organization. Most organizations that support diversity in their organizations focus more on the smaller groups that aim to employ women. And these groups are more interested in applying for jobs in places where diversity in the workplace is supported. (Perkins et al., 2000).

An important factor is the diversity of employees, which can be of different types starting from the demographic, informative, cultural, etc. All these types of diversity that a working team can contain serve as obvious features that make people different from other team members and at the same time collaborate with them. (DiTomaso et al., 2007).

Organizations that have diversity in their composition are those that operate successfully thus working in accordance with their strategy. Companies that work with teams that are different from each other, and work with a strategy makes the company innovative and achieve progress. On the contrary if these teams work without strategy then there will be no effect on progress. (Richard et al., 2004). 
The organization operates in a changing environment where the change in the age, gender, level of education of employees imposes on the organization the restructuring of organizational cultures, values and norms. (Sung and Choi, 2019)

The diversity that exists between people contains all the differences between the traits which make others think that the other person is different from them. Two main features have been identified that help in the search for diversity based on social sharing and the decision-making part of information. Social division includes age, gender, race while information decision making is based on information diversity (Williams and O'Reilly, 1998). Based on what was said above we need to look at the impact of diversity on group success. Diversity of social categories means division and categorization which creates problems in group relationships. While the diversity of information positively affects the success of the group because everyone has an idea which in the end can serve as a more accurate information to make a decision. (vanKnippenberg et al., 2004).

Professionals around the world have long faced a variety of changes such as demographics, socio-political, technological advances, globalization, etc. Consequently we need to know how to manage diversity by focusing on differences between people effectively. Managing these differences or diversity is a cost, but when implemented properly it brings many good things to the company, starting with more talented people, increasing employee motivation, increasing innovation. In addition, good diversity management helps the company to have a good position in the market. (Armstrong et al., 2010). While diversity management is of great importance, it is also a cost to the organization. In cases when the management does not go properly, these costs aggravate the financial situation of the company. Costs that have to do with the loss of many cases by the company, reduction of group synergy, the need for additional work in coordination within the company for anything new that the company faces. (Slater, Weigand, \& Zwirlein, 2008).

According to Riccò (2012), even there could be differences or similarities between employees in terms of how they see the life, workplace and how they relate to other people, in general that doesn't mean neither good or bad but for sure this will influence his or her ability to work with other organization members. If such organizations create an inclusive workplace for their members no matter of any kind of diversities they have, where everyone can express themselves freely and be proud of heterogeneity between the members, this can create new ways of communicating and collaborating (Pless \& Maak, 2004).

According to Chavez and Weisinger (2008), effective learning is achieved through the practical way where various topics related to diversity, heterogeneity, interpersonal relationships and others, can be illustrated with case studies. Such forms of training are used by management staff to better understand diversity and its impact within the members of the organization they lead, an impact which can be positive or negative.

According to economic theory, the diversity of staff in the workplace can affect the success of the company in various ways. For example, a diversity in the field of education enables the dissemination of knowledge to staff, which has a direct impact on increasing the success of the company. (Lazear, 1999)

In most cases it is preferable to have diversity within the company, but there are some activities which require to have similar attributes among the staff. This similarity is precisely in the education and skills of the staff as the firms that increase their profit must adapt and also have workers with similar education. Other factors do not mean to be similar because for example different ages in the workplace complement each other. Younger workers are better able to work with the times with different technological innovations while older workers have more experience in the way the firm operates. (Lazear, 1998).

The more heterogeneous the group, the more heterogeneous ideas they have, thus presenting new ideas which constitute a greater amount of knowledge and information valuable for dealing with any situation that arises. Each person different from the other as in age, gender or race has a different experience that contributes to creativity. Only by working together can different ideas and experiences be disseminated to create an easier approach to problem solving. (Janis, 1972).

\section{Method}

Population and samples-The population of this research consists of banking and microfinance institutions which operate in Kosovo. The choice of these institutions is not random because the banking sector has many employees which helps us to provide as much information about diversity and its impact on productivity. Through this we can see how this phenomenon is in our country.

Instrument and procedure-The instrument used in this research is the questionnaire, which was distributed to 20 managers and 30 employees of the banking sector. The questionnaire contains 25 closed questions where the evaluation is based on the Likerti scale with $1-5$ options to choose from. The questions were understandable, and 
the distribution was done physically in the branches. Through this paper we will try to see the real impact that diversity has on productivity growth.

Research questions-Below are the initial questions where this paper focuses. The research questions are as follows:

- Does diversity related to easier problem solving?

- Does the age of employees affect creativity?

- Is group work more productive when there is diversity?

Hypotheses-Hypotheses emerge from the research questions:

H1: Diversity related to easier problem solving

H2: Employee age affects creativity

H3: Group work is most productive when there is diversity

\section{Results}

While diversity is very important in group work, from the analysis of the data we will see how the hypotheses stand, will be confirmed, or rejected based on the answers of the respondents.Correlation is a statistical quantity that helps us understand the relationship between two variables. So through correlation we discover the causal link. The correlation coefficient gives us a mathematical value to measure the power of linear correlation between two variables.

\section{Testing the first hypothesis}

H10. There is a significant positive correlation between the impact of diversity and easier problem solving.

H1a: There is no significant correlation between the impact of diversity and easier problem solving.

Table 1. Correlation between diversity and the easiest solution to problems.

\begin{tabular}{llll}
\hline Correlations & & & \\
\hline & & DIVERSITY & $\begin{array}{l}\text { The easiest solution to } \\
\text { problems }\end{array}$ \\
\hline DIVERSITY & Pearson Correlation & 1 & $.750^{* *}$ \\
& Sig. (2-tailed) & & .002 \\
& $\mathrm{~N}$ & 50 & 50 \\
\hline The easiest solution to problems & Pearson Correlation & $.750^{* *}$ & 1 \\
& Sig. (2-tailed) & .002 & \\
& $\mathrm{~N}$ & 50 & 50 \\
\hline \multirow{2}{**}{. Correlation is significant at the 0.01 level (2-tailed). } & & \\
\hline
\end{tabular}

To assess whether the test is important or not we have to look at the level of significance, where if that level is then the value of $p$ is less than or equal to 0.05 then we say that the test is important and if the level of significance is the value of $\mathrm{p}$ is more greater than 0.05 we say the test is not significant. Here we have two variables, the first variable is diversity while the second variable is the easiest solution to problems.

Based on the correlation results we see that the Variables are highly correlated with each other, and we can say that the hypothesis is confirmed. So diversity has an impact on the easier solution of problems. After seeing the impact of diversity on problem solving, we will also look at the graphical representation of what percentage of respondents want to have diversity in the country where they work. 


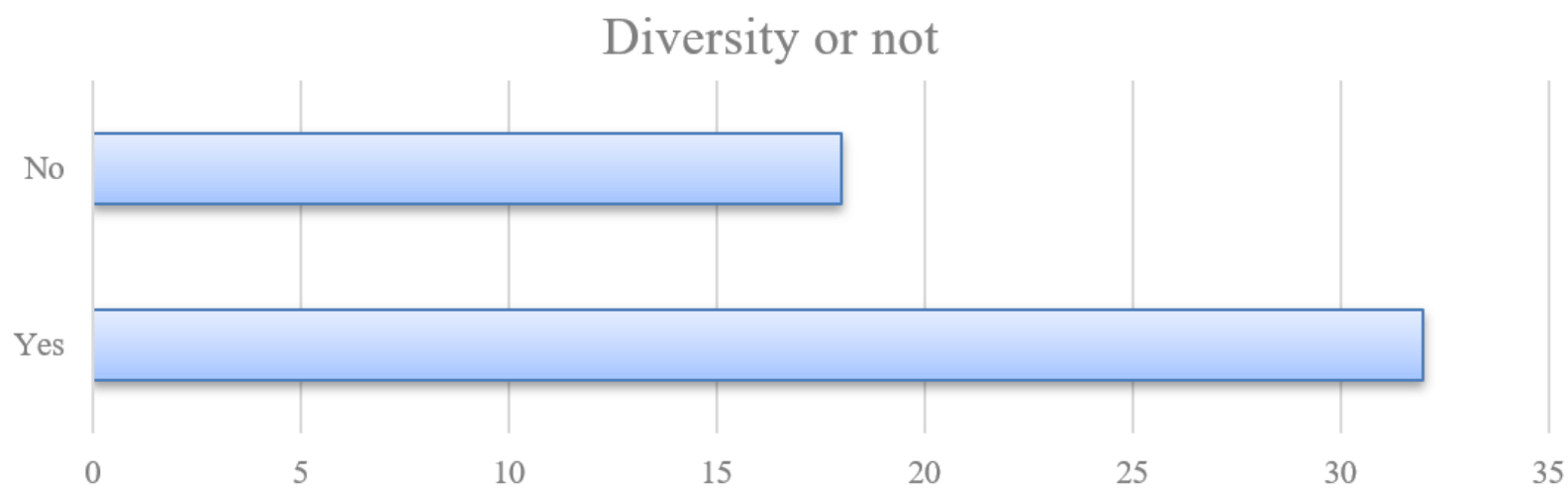

Figure 1. Presentation of the point of view of respodents whether it is good to have diversity in the company or not

From the answers of the respondents to the question whether they want to have diversity in the country where they work, about $65 \%$ of them have expressed a desire and have seen it as something positive unlike the other $35 \%$ who have not aroused any interest. In each organization where we work with people and through them, we encounter different ages of employees thus creating a diversity within the organization. In the following we will see how age influences creativity and innovation.

\section{Testing of the second hypothesis}

H10. Employee age affects creativity

H1a: Employee age does not affect creativity

We will test the hypothesis with the statistical test with a sample.

Table 2. Descriptive statistics on the impact of employee age on creativity

\begin{tabular}{lllll}
\hline One-Sample Statistics & \multicolumn{5}{l}{} \\
\hline & $N$ & Mean & Std. Deviation & Std. Error Mean \\
\hline Age of employees & 50 & 99.850 & 119.66896 & 26.75879 \\
Creative ideas & 50 & 3.650 & 1.3485 & .3015 \\
\hline
\end{tabular}

Table 3. Statistical test on a sample on the influence of employees' age on creativity

\begin{tabular}{|c|c|c|c|c|c|c|c|}
\hline \multicolumn{8}{|l|}{ One-Sample Test } \\
\hline & \multicolumn{7}{|c|}{ Test Value $=0$} \\
\hline & \multirow[b]{2}{*}{$\mathrm{T}$} & \multirow[b]{2}{*}{ Df } & \multirow[b]{2}{*}{ Sig.(2-tailed) } & \multirow[b]{2}{*}{ Mean Difference } & \multicolumn{3}{|c|}{$\begin{array}{l}95 \% \text { Confidence } \\
\text { Interval of } \\
\text { Difference }\end{array}$} \\
\hline & & & & & Lower & Upper & \\
\hline Age of employees & 3.731 & 19 & .001 & 99.85 & 43.843 & 155.8568 & \\
\hline Creative ideas & 12.105 & 19 & .000 & 3.650 & 3.019 & 4.281 & \\
\hline
\end{tabular}

Our variables are employee age and creative ideas.So, analyzing the significance value, which is a value less than 0.05 , respectively 0.001 (Age of employees) and 0.000 for the constant (creative ideas) means that this result is statistically significant, because from data collected from the survey, it turns out that the testing of this variable is true. So, the first hypothesis is accepted or considered. The interpretation would be this: The age of the employees affects creativity.

As we can know, every age in the workplace contributes, but for creativity the younger ages stand out. Through a diagram we will see the age of our respondents. 


\section{AGE OF EMPLOYEES}

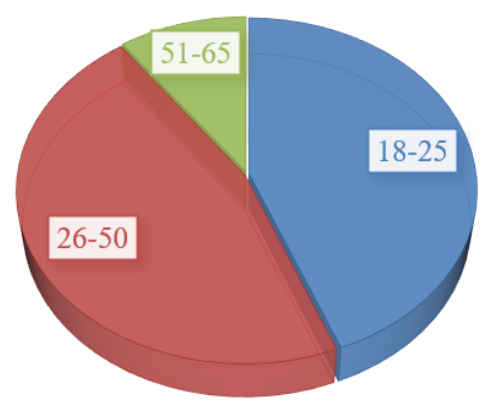

Figure 2. Graphic representation of the age of the respondents

What stands out is that in the banking sector older ages do not constitute a large number, implying the orientation of managers towards younger, more creative, and innovative ages. According to the analysis, $45 \%$ of respondents are young people aged 18-25.

When asked by the respondents how creative they are from 1-5, we received very interesting answers from different ages.

\section{How many employees think they are creative}

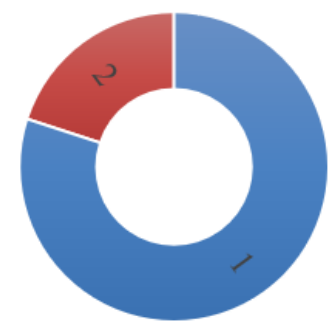

When asked how creative they think they are, about $80 \%$ of their employees answered that they think they are creative, while the rest, mostly older, did not consider themselves to be so creative.

\section{Testing of the third hypothesis}

Group work is most productive when there is diversity

It is always said that unity makes power and in addition the diversity within the group influences the work to progress. To see if diversity has an impact on group work to be more productive, we will analyze it with the Crosstabs option in SPSS.

Table 4. Case processing summary

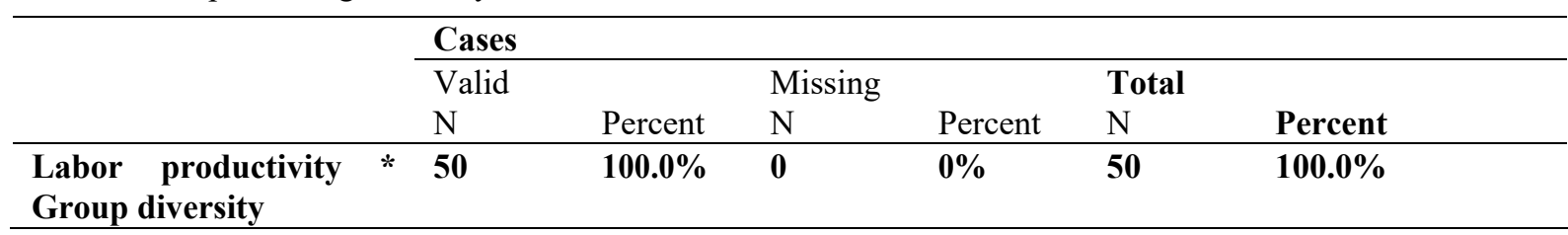

Table 5. Crosstabulation of labor productivity and group diversity

\begin{tabular}{lllll}
\hline Labour productivity * Group diversity & & & \\
\hline Count & & \multicolumn{2}{l}{ Group diversity } & Total \\
\cline { 2 - 5 } & & yes & no & \\
\hline Labor productivity & yes & 30 & 8 & 38 \\
\cline { 2 - 5 } & no & 7 & 5 & 12 \\
\hline Total & & $\mathbf{3 7}$ & $\mathbf{1 3}$ & $\mathbf{5 0}$ \\
\hline
\end{tabular}


It is clear that our hypothesis is supported by field findings, so the diversity within the working group influences the work to be performed with greater productivity.

\section{Discussion}

Through this paper, the purpose of which was to investigate the role of diversity in productivity, we reach some conclusions which are supported by our findings. The role of diversity is very large by thus helping to solve problems more easily, different ages within the organization help us to have higher creativity as well as work is more productive in an environment where there is diversity. So the presence of diversity carries weight in the success of the individual within the company and the company as a whole. Based on the results of the work we see that diversity is necessary to achieve success, to differentiate from others and to be more creative. knowing the value we can collaborate and be successful together. The focus of companies on staff diversity is also not very clear as they are a bit skeptical about including people of different cultures in the work team. While diversity has many positive aspects for the productive operation of the company, this phenomenon should be further promoted for success, creativity and innovation within the company.

First as we expected in testing the correlation between diversity and easier problem solving it turned out that there is a positive correlation with a significance of .002 . Secondly,while age diversity plays an important role in increasing creativity, our findings showed a positive correlation with a degree of reliability.001. Thirdly we researched group productivity when there is diversity and our findings have shown positive correlation the largest percentage of respondents responded that with group diversity the highest work productivity is achieved.

Based on our results we have not found the same findings from other authors but their findings can be well related to the topic of the paper. The climate of diversity has a great importance in the work and success within the company. Based on this according to Singh et.al., (2013) it has been found that there is a positive relationship between the various factors which have diversity as a starting point. Thus starting from the climate of diversity and psychological security with a positive relationship and with result $(B=0.86, t=9.24, p<.01)$ influencing with another positive relationship between psychological security and group performance $(B=0.17, t=3.16, p$ $<.01)$.Based on Kunza et al., (2013), we can see what the presence of age diversity in the company faces. So according to him there is a positive relationship between age diversity and age discrimination with result $(\mathrm{r}=0.28$, $\mathrm{p}<0.001$ ) which negatively affects the performance of the company, ie constitutes a negative relationship with the success of the company with results $(r=-0.23, p<0.01)$.

From the above conclusions derive the recommendations that each company or organization that works with people and through them, pay attention to the main factors that affect the motivation of employees and increase the quality of work. Starting from here each challenge which companies face nowadays is more affordable if within it we have staff of different ages, genders and cultures because the exchange of different experiences leads to shorter and more creative ways to solve problems.

The challenge during the research was that the questionnaire had difficulty in distribution, as it is the time of the COVID-19 pandemic, and the meetings were more limited, furthermore the limitation of the study was the fact that respondents may not have responded in the form they really think due to fear of retribution from their supervisors. Give more importance to human resources from recruitment to employment and further development, because only the right person in the right place needs the company to move forward.

\section{References}

Armstrong, C., Flood, P. C., Guthrie, J. P., Liu, W., MacCurtain, S., \& Mkamwa, T. (2010). The impact of diversity and equality management on firm performance: Beyond high performance work systems. Human Resource Management, 49(6), 977-998. https://doi.org/10.1002/hrm.20391

Chavez, C. I., \& Weisinger, J. Y. (2008). Beyond diversity training: A social infusion for cultural inclusion. Human resource management: Published in cooperation with the school of business administration, the University of Michigan and in alliance with the Society of Human Resources Management,47(2), 331-350. https://doi.org/10.1002/hrm.20215

DiTomaso, N., Post, C., \& Parks-Yancy, R. (2007). Workforce diversity and inequality: ower, status, and numbers. Annual Review of Sociology, 33(1), 473-501.

Janis, I. L. (1972). Victims of Groupthink: A psychological study of foreign-policy decisions and fiascoes. https://doi.org/10.1146/annurev.soc.33.040406.131805

Kremer, M. (1993). The O-ring theory of economic development. The Quarterly Journal of Economics, 108(3), 551-575. https://doi.org/10.2307/2118400 
Kunze, F., Boehm, S., \& Bruch, H. (2013). Organizational performance consequences of age diversity: Inspecting the role of diversity-friendly HR policies and top managers' negative age stereotypes. Journal of Management Studies, 50(3), 413-442. https://doi.org/10.1111/joms.12016

Lazear, E. P. (1998). Personnel economics for managers (p. 316). New York: Wiley.

Lazear, E. P. (1999). Globalisation and the market for team-mates. The Economic Journal, 109(454), 15-40. https://doi.org/10.1111/1468-0297.00414

Mfene, P. N. (2010). Enhancing supervisor and subordinate communication in diversity management. Africa Insight, 40(2), 141-152. https://hdl.handle.net/10520/EJC17639

Perkins, L. A., Thomas, K. M., \& Taylor, G. A. (2000). Advertising and recruitment: Marketing to minorities. Psychology \& Marketing, 17(3), 235-255. https://doi.org/10.1002/(SICI)1520-6793(200003)17:3<235:: AID-MAR3>3.0.CO;2-\#

Pless, N., \& Maak, T. (2004). Building an inclusive diversity culture: Principles, processes and practice. Journal of business ethics, 54(2), 129-147. https://doi.org/10.1007/s10551-004-9465-8

Riccò, R. (2012). Utilizing a new human relations framework to leverage workforce diversity. In Handbook of research on workforce diversity in a global society: Technologies and concepts (pp. 440-462). IGI Global. https://doi.org/10.4018/978-1-4666-1812-1.ch026

Richard, O. C., Barnett, T., Dwyer, S., \& Chadwick, K. (2004). Cultural diversity in management, firm performance, and the moderating role of entrepreneurial orientation dimensions. Academy of Management Journal, 47(2), 255-266. https://doi.org/10.5465/20159576

Singh, B., Winkel, D. E., \& Selvarajan, T. T. (2013). Managing diversity at work: Does psychological safety hold the key to racial differences in employee performance?. Journal of Occupational and Organizational Psychology, 86(2), 242-263. https://doi.org/10.1111/joop.12015

Slater, S. F., Weigand, R. A., \& Zwirlein, T. J. (2008). The business case for commitment to diversity. Business horizons, 51(3), 201-209. https://doi.org/10.1016/j.bushor.2008.01.003

Sung, S. Y., \& Choi, J. N. (2021). Contingent effects of workforce diversity on firm innovation: high-tech industry and market turbulence as critical environmental contingencies. The International Journal of Human Resource Management, 32(9), 1986-2012. https://doi.org/10.1080/09585192.2019.1579243

Van Knippenberg, D., De Dreu, C. K., \& Homan, A. C. (2004). Workgroup diversity and groupperformance: an integrative model and research agenda",Journal of Applied Psychology, Vol. 89No. 6, pp. 1008-1022 https://doi.org/10.1037/0021-9010.89.6.1008

Williams, K. Y., \& O’Reilly, C. A. (1998). Demography and diversity in organizations: a review of 40 years of research. Research in Organizational Behavior, 20, 77-140.

\section{Copyrights}

Copyright for this article is retained by the author(s), with first publication rights granted to the journal.

This is an open-access article distributed under the terms and conditions of the Creative Commons Attribution license (http://creativecommons.org/licenses/by/4.0/). 